\title{
EL TURISMO DE SALUD DESDE EL ENFOQUE SISTÉMICO: APLICACIÓN A LA PROVINCIA DE ALICANTE
}

\author{
Elke Hersch Glass \\ Universidad de Alicante \\ https://orcid.org/0000-0003-0683-8712
}

\begin{abstract}
RESUMEN
El propósito de ese trabajo se centra en identificar los principales fundamentos condicionantes de la demanda y de la oferta en el turismo de salud sobre la base de la teoría de sistemas. Además, se lleva a cabo un análisis empírico del turismo médico, turismo wellness y turismo medical wellness de la provincia de Alicante desde este enfoque. Metodológicamente el trabajo se fundamenta en una tarea de sistematización de la bibliografía anglo-germánica existente sobre el tema y no traducida al español. La relevancia de este artículo la constituye la novedad de su enfoque metodológico y su aplicación sobre el turismo de salud, así como su aplicación a un espacio turístico consolidado, como es la provincia de Alicante, donde esta modalidad está implantada y viene funcionando desde hace décadas.
\end{abstract}

Palabras clave: turismo de salud; turismo médico; turismo medical wellness; turismo wellness; Alicante.

\section{Health tourism from the systemic approach: application to the province of Alicante}

\begin{abstract}
The purpose of this paper is to identify the main determinants conditioning supply and demand in health tourism based on systems theory. An empirical analysis of medical tourism, wellness tourism and medical wellness tourism in the Province of Alicante is carried out, applying the aforementioned approach. Methodologically, the work is based on the task to systematize the existing Anglo-German literature on the subject that has not been translated into Spanish. The relevance of this article lies in the novelty of the methodological approach
\end{abstract}

Fecha de recepción: 13 de febrero de 2020.

Fecha de aceptación: 3 de julio de 2020.

* E-mail: elke.hersch@gmail.com 
and its application to health tourism as well as its application to a consolidated tourist area, such as the Province of Alicante, where this modality is established and has been working for decades.

Keywords: health tourism; medical tourism; medical wellness tourism; wellness tourism; Alicante.

\section{INTRODUCCIÓN}

El turismo de salud es un concepto complejo que se desarrolla a partir de dos vertientes: por una parte, en el propio ámbito turístico con ofertas de salud orientadas al consumo turístico, lo que se podría denominar en sentido estricto como turismo de salud, y que en la provincia de Alicante es observable desde la década de 1990. Y por otra, desde el ámbito médico a partir del año 2000, complementando su actividad con ofertas turísticas, es decir, mediante modos operativos propios del sistema turístico, lo que sería el turismo médico. De este modo la oferta es generada desde diferentes tipos de establecimientos, tanto médicos como turísticos, adoptando distintas formas.

Puede afirmarse, con carácter general, que toda oferta presupone la existencia de una demanda, o dicho de otro modo, la existencia previa de determinada demanda resulta elemento esencial en la generación de la oferta. A su vez la demanda viene determinada por fundamentos de diverso tipo: sociocultural, económico, político, tecnológico y ecológico. Así pues, el presente trabajo, tras una reflexión sobre el concepto de turismo de salud y los enfoques en su estudio, trata de identificar los principales fundamentos condicionantes de la demanda y de la oferta de esta modalidad de turismo sobre la base de su aplicación empírica a la provincia de Alicante y acotada temporalmente desde 2016 hasta 2019. Asimismo, se analizan los establecimientos receptores desde la perspectiva de su oferta, con el fin de poner al descubierto cuáles de los fundamentos de cada tipo de demanda son atendidos por el turismo de salud alicantino. Como planteamiento teórico, y dada la complejidad estructural del turismo de salud, el análisis se realiza desde un enfoque sistémico, pues este marco de análisis facilita la comprensión integral del objeto de estudio.

\section{CONCEPTUALIZACIÓN DEL TURISMO DE SALUD Y SU SISTEMATIZA- CIÓN}

El turismo de salud constituye, como se acaba de indicar, un concepto complejo del turismo, pues basta atender a la tipología de establecimientos y modalidades para tener una noción clara de ello. Además, es preciso considerar su oferta extremamente amplia, como bien puntualiza Connell: "existe un continuo desde el turismo de salud (o bienestar) que involucra ejercicio de relajación y masaje, cirugía estética (que va desde la odontología hasta la intervención sustancial, entre otras), cirugía (como reemplazos y trasplantes de cadera etc.), procedimientos reproductivos e incluso turismo de eutanasia" (2013:3). Por 
otra parte, la movilidad de pacientes entre países favorece la aparición de nuevos procesos, así como la participación de mediadores entre pacientes internacionales, redes de hospitales y destinos vinculados a recientes necesidades puestas de manifiesto, por ejemplo, en el grupo de mayores, o son producto del cambio de valores de vida, o de la alta conciencia de la sustentación de la salud.

La complejidad también se observa en la actual reorientación del sector. Si bien desde sus orígenes una parte de los establecimientos hoteleros se habían especializado en la prestación de servicios en prevención, balneología o rehabilitación; con la diversificación acontecida en las últimas décadas, parte de la hostelería, ajena en principio a estos ámbitos, se reorientó a ellos ofertando salud, como sucede por ejemplo en los hoteles que ofrecen wellness o medical wellness. Esta reorientación brindó nuevas oportunidades de negocio, pero también incrementó la complejidad y las responsabilidades surgidas en la atención de tipo sanitario o de higiene, así como los procesos asociadas al tratamiento y cuidado personal con todas sus consecuencias. Por otra parte, la investigación de turismo es interdisciplinaria, por tanto, se consideran diferentes aspectos y métodos. Tal complejidad del turismo de salud favoreció la aplicación en su análisis de la teoría de sistemas, teoría susceptible de actuar integrando distintas disciplinas, elementos y relaciones, gracias a un lenguaje común y a su base conceptual.

La base conceptual de la teoría de sistemas fue iniciada en lengua inglesa por Bertalanffy en diferentes trabajos y definida en 1968 en su General System Theory. En lengua alemana fue aplicada por Ulrich en un estudio de 1968 titulado, Die Unternehmung als produktives soziales System (La empresa como sistema social productivo), publicado en español en 1977. Para Bertalanffy (1967:69) "un sistema puede ser definido como un complejo de elementos relacionados entre ellos. Existen principios generales para los sistemas, independientemente de la naturaleza de los elementos componentes y de las relaciones o fuerzas entre ellos" (Lohman y Panosso, 2017:3). La teoría general de sistemas permite que una actividad compleja sea analizada como un todo, un sistema unido, o dividido en partes con el fin de facilitar su comprensión y estudio. Para que una actividad compleja sea considerada sistema debería tener "un entorno (la ubicación del sistema), unidades (partes del sistema), relaciones (las relaciones entre las unidades del sistema), atributos (la calidad de las unidades y el sistema en sí), entrada (lo que ingresa al sistema), salida (lo que sale del sistema), retroalimentación (control del sistema para que funcione correctamente) y un modelo (un diseño de sistema para facilitar su comprensión)" (Lohman y Panosso, 2017:3). En cuanto a Ulrich, este autor considera la teoría general de sistemas como la ciencia formal de la estructura, de las interconexiones y del comportamiento de cualquier sistema, por lo que entiende que "un sistema es una totalidad ordenada de elementos entre los que existen o pueden establecerse relaciones" (Ulrich, 1968:105ss).

Según la literatura especializada, uno de los primeros análisis del turismo que utiliza la teoría de sistemas de Bertalanffy fue escrito por Raymundo Cuervo en 1967 en su libro, El Turismo como medio de comunicación humana, Cuervo describe el turismo como un conjunto de relaciones, servicios e instalaciones que se generan en ciertos movimientos humanos (Cuervo, 1967:29 en Lohman y Panosso, 2017:4).

No obstante, fue Kaspar quien en 1978 aplicó por primera vez la teoría de sistemas de Ulrich al turismo de salud al introducir en su modelo los denominados "establecimientos 
para sanar", ampliando de este modo la perspectiva del análisis sistémico a esta modalidad. Dice Kaspar: "el turismo no puede ser considerado en forma aislada del medio ambiente en sentido amplio. El hecho de que la gente esté en el centro del turismo nos obliga a abstenernos de verlo de forma aislada. Debemos alejarnos del pensamiento unidimensional e intentar abordar los problemas del turismo en el mayor número de dimensiones posibles. Es comprensible que, de acuerdo con la tarea establecida, consideremos principalmente el entorno económico. En este esfuerzo, incluiremos en nuestras consideraciones, en la medida de lo posible, las dimensiones interdisciplinarias del entorno social, tecnológico y ecológico. Es particularmente importante señalar las interrelaciones entre los problemas. Para ello hacemos uso de la teoría de sistemas" (Kaspar, 1996a:11).

Por consiguiente, el modelo de Kaspar desarrolla un sistema de turismo abierto, es decir, abierto en sus relaciones, dependencias y influencias hacia su entorno, pues el sistema de turismo de Kaspar, como ya se ha indicado, está en relación de interacción con diferentes entornos, que este autor integra en lo que considera un "sistema de orden superior", compuesto por lo que denomina: entorno económico, socio-cultural, tecnológico, político y ecológico. En su concepción, el sistema turístico está compuesto de dos subsistemas a los cuales denomina: "subsistema del sujeto de turismo" y "subsistema del objeto de turismo". El objeto de turismo se encuentra a su vez integrado por tres subsistemas: las empresas turísticas, el destino turístico, y las organizaciones turísticas. En el objeto de turismo, Kaspar incluye todo "lo que puede ser susceptible de estimular un desplazamiento de tipo turístico en la naturaleza, cultura, economía y sociedad” (1996a:15). El objeto de turismo se corresponde con la "oferta originaria" del destino (naturaleza, infraestructura, circunstancias socio-culturales) y la "oferta derivada" de la actividad: establecimientos de desplazamiento, de la estancia, de mediación etc. (1996a:68).

Kaspar (1996a), Müller (1997) y Bieger (2006) aluden claramente a las ventajas de la teoría de sistemas. Se indica que entre el turismo y su entorno existen múltiples relaciones, redes y subsistemas. Además, el producto de turismo está compuesto de muchos servicios parciales, pues realmente se trata de un conjunto de servicios (Kaspar, 1996a:11). Lohman y Panosso, exponen las ventajas y desventajas para el estudio del turismo utilizando la teoría general de sistemas. Como ventajas indican que, "al crear un modelo (diseño conceptual) se tiene una visión general del turismo 'total'. Es posible segmentar el sistema en partes y estudiarlas por separado, además, es posible separar el sistema turístico de otros sistemas, facilitando así su estudio y permitiendo un estudio interdisciplinario del turismo". Sobre las desventajas de la teoría general de sistemas escriben: "A pesar de que separando el sistema turístico de otros sistemas facilita el estudio, también conduce a una visión fragmentada de su objeto" y añaden que, "al considerar separadamente el turismo como un sistema, no se debe olvidar que el turismo forma parte de un sistema más amplio, como es el sistema social" (2017:4). Modelos de enfoques de presentación del turismo como sistema se encuentran en Krippendorf (1984), Mill y Morrison (1987), Getz (1986), Leiper (1990) o Müller (1997). 


\section{Figura 1 \\ SISTEMA DEL TURISMO SEGÚN KASPAR (1996a)}

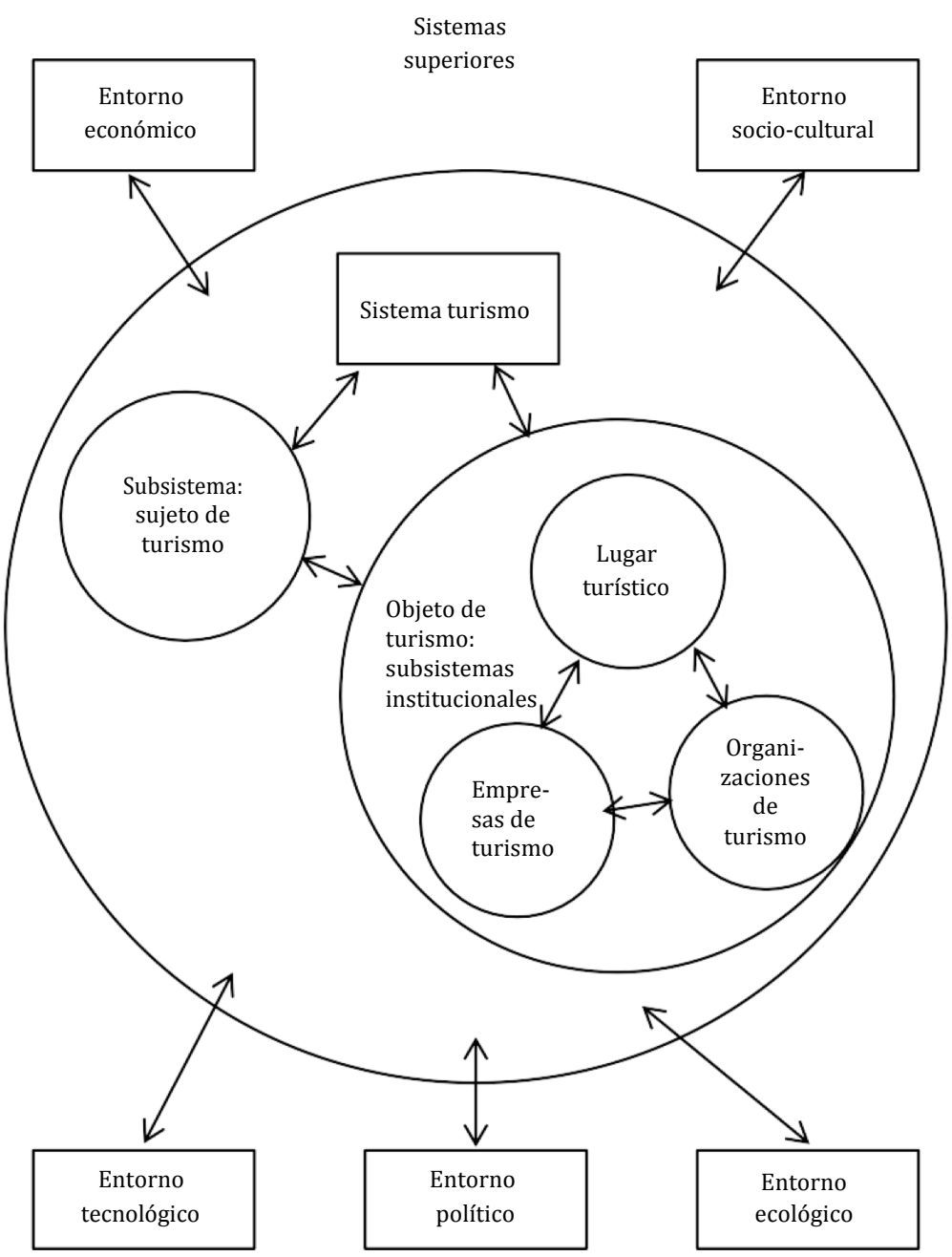

Fuente: Kaspar (1996a:12)

Ahora bien, con el fin conocer la recepción de los fundamentos generados en el "sistema de orden superior" de Kaspar por parte de los establecimientos que reciben pacientes y huéspedes de salud, y que "buscan satisfacer necesidades", resulta imprescindible analizar las ofertas específicas integrantes de la "oferta derivada" de los establecimientos (empresas) del turismo de salud. Los diferentes tipos de ofertas turísticas de los establecimientos médicos como las clínicas y hospitales, también se pueden analizar a través de la teoría de Kaspar, pues este autor incluye en su teoría los "alojamientos de balneario y cuidado 
de la salud", y son para él: "empresas turísticas particulares de primer área de servicio". Sobre estos establecimientos observa que:"el diferenciador más destacado al contrario de todos los tipos de establecimientos hoteleros u otros alojamientos es su principal desempeño operativo en forma de atención médica y de enfermería, incluidas las terapias específicas que los caracterizan (cura de baño, tratamientos climáticos, etc.). El alojamiento y las comidas son sólo servicios subsidiarios" (1996a:86). Aunque Kaspar recoge bajo el término "terapias específicas" una oferta amplia e indefinida, en la cual podría tener cabida la modalidad wellness, conviene matizar con mayor precisión esta oferta.

Mientras que Müller y Lanz-Kaufmann (2001:6) señalan como integrantes de esta oferta un paquete de servicios destinado al cuidado individual como paradigma de salud y enfocado a intervenciones que se basan en el estilo de vida en áreas de entrenamiento físico, cuidado de la belleza, nutrición saludable, relajación/meditación y actividad mental/ educación; Voigt (2014:28) indica que en este concepto faltan las terapias de medicina complementaria y alternativa (CAM), pues "sabiendo que los servicios e instalaciones de wellness cambian y se desarrollan constantemente", Voigt y Laing (2013:36) establecieron tres diferentes tipos de ofertas que engloban en el concepto de proveedores de turismo de salud: proveedores de turismo médico, proveedores de turismo wellness y ofertas que se "superponen" en los proveedores de medical wellness. Aparte de los proveedores de "turismo médico puro", distingue los proveedores del "turismo wellness puro" y los "superpuestos", es decir, los mixtos que contienen en principio ofertas de los otros dos grupos. Con los proveedores de "turismo wellness puro" se refieren, entre otras, a las ofertas complementarias y alternativas de medicina conocidas en la literatura especializada anglosajona como CAM (Voigt, 2014:35).

Voigt (2014:28) clasifica la totalidad mundial de las ofertas wellness en once categorías: 1. Tratamientos corporales y faciales, 2. Tratamientos e instalaciones a base de agua y baños de sudor, 3 . Terápias manuales y manipulativas basadas en la presión manual, 4. Plantas medicinales y remedios naturales, 5. Nutrición y dieta saludable, 6. Ejercicio y entrenamiento, 7. Intervenciones mente / cuerpo, 8. Técnicas de mediación y relajación, 9. Terapias expresivas y artes creativas, 10. Terapias energéticas y new age, 11. Actividades educativas: asesoramiento, talleres y seminarios, enseñanzas religiosas. La clasificación de Voigt permite ampliar la teoría de sistemas de Kaspar mediante la aportación de un análisis detallado de la oferta tipo turismo wellness y ofertas mixtas. Con esta aportación se cubre la amplia heterogeneidad que se observa en el análisis del turismo médico, turismo wellness o en una de sus formas mixtas. No obstante, se puede afirmar que en el conjunto de servicios ofertados por los establecimientos debe existir algo común e imprescindible que es el concepto "turismo".

Sobre los tipos de establecimientos que participan en el turismo de salud, Voigt y Laing (2013:37) denominan proveedores del turismo médico a las clínicas privadas y las corporaciones de hospitales. Consideran proveedores de turismo wellness a los hoteles de spa y belleza (beauty spa hotels/resorts), lifestyle resorts y spiritual retreats. Como establecimientos proveedores mixtos consideran los therapeutic lifestyle retreats, wellspitals, health clusters (por ejemplo, los balnearios tradicionales europeos), medhotels y medical spas.

En otras publicaciones se incluyen como establecimientos de turismo wellness, el wellness hotel (Müller y Lanz-Kaufmann, 2001:7) así como el hotel de pacientes 
(Illing, 2009:121). Dentro de los establecimientos mixtos se conocen, además de los indicados por Voigt, la clínica de rehabilitación (Illing, 2009:120), el medical wellness hotel que define Krczal (2011:174) y el care hotel (hotel con atención de enfermería) según (Rosowski, 2008).

\section{Figura 2 \\ PROVEEDORES (ESTABLECIMIENTOS) DE TURISMO DE SALUD SEGÚN VOIGT Y OTROS}

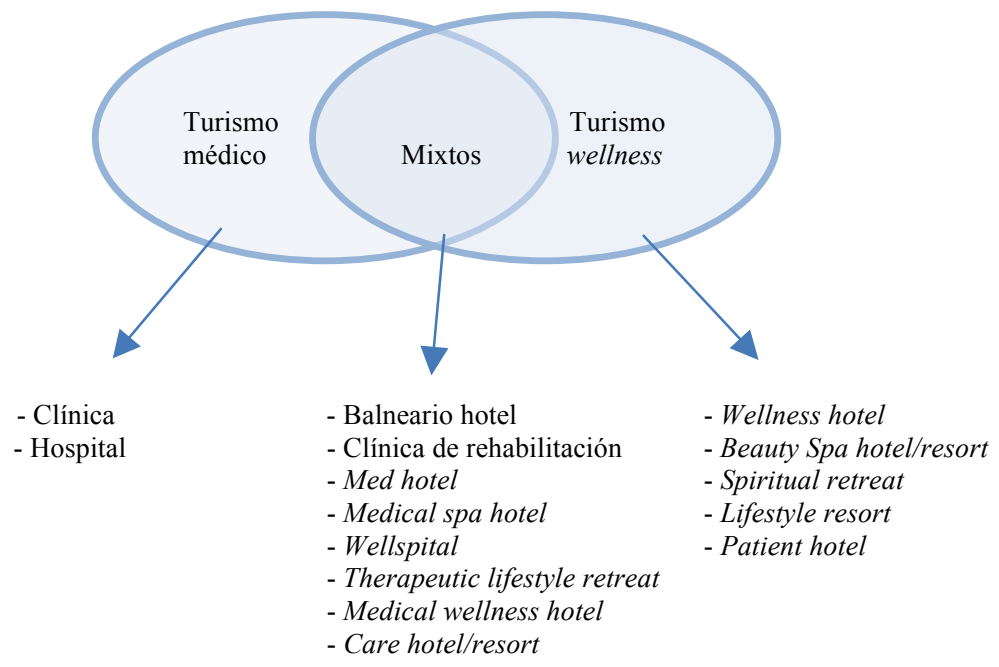

Fuente: Voigt (2014) y elaboración propia.

\section{ESTADO DE LA CUESTIÓN Y ENFOQUES DE LA LITERATURA EN EL ESTUDIO DEL TURISMO DE SALUD}

El trabajo llevado a cabo se fundamenta en una tarea de sistematización de la bibliografía anglo-germánica existente sobre el tema. En particular, se ha prestado especial atención a aquellas investigaciones no traducidos al español, para lo cual se ha realizado una revisión de la bibliografía especializada tanto en el ámbito germano como en el anglófono, con el fin de identificar aquellos aspectos esenciales o nucleares que constituyen los estudios del turismo de salud en estos ámbitos y que resultan plenamente pertinentes a la presente investigación. Se ha revisado la literatura sobre el tema procedente de países como Suiza, Austria y Alemania, donde existe una larga tradición en el estudio del turismo de salud, y otros estudios publicados en Estados Unidos, Reino Unido o Australia.

Concretamente en Alemania, Nahrstedt (1996) fue uno de los primeros en iniciar la investigación científica en estas áreas, publicando sus trabajos sobre el turismo de salud tradicional y el desarrollo del turismo wellness desde finales de los años 1990 hasta 2008, dos años antes de su fallecimiento. Sobre el turismo de salud en Europa, Rulle (2008) publicó una monografía en lengua alemana dedicada a los balnearios tradicionales 
europeos y sus tendencias de desarrollo y estrategias de diversificación, ampliada con un estudio sobre la demanda de los huéspedes en el declarado "destino de salud" en la región de Mecklenburg-Vorpommern (Rulle et al., 2010) orientado al turismo medical wellness.

Sin embargo, fue principalmente el Dr. Kaspar, de la Universidad de St. Gallen (Suiza) quien, en el ámbito de la literatura del turismo de salud, ofreció por primera vez en sus publicaciones el fundamento teórico del análisis sistémico aplicado al turismo de salud tradicional y a los inicios del turismo wellness (Kaspar, 1978, 1996a) así como Kaspar y Fehrlin (1984). Lanz-Kaufmann(1999, 2002) y Müller y Lanz-Kaufmann $(2000,2001)$ han continuado la investigación sistémica en el campo de salud preventiva y bienestar desde la Universidad de Berna con publicaciones sobre el turismo wellness de la industria hotelera suiza. Estas investigaciones han servido de base en muchas interpretaciones sobre el tema wellness en el ámbito germano y anglófono.

En Austria, Weiermeier y Steinhauser (2003) se han centrado en el estudio del alpine wellness, Krczal (2011) sobre la calidad de medical wellness e Illing (2000, 2002, 2004 y 2009) ha realizado aportaciones con sus estudios sobre el turismo de salud: turismo médico, turismo de rehabilitación, turismo wellness y medical wellness.

En cuanto a la literatura en lengua inglesa, algunos autores han realizado trabajos de tipo conceptual y otros tratan distintas perspectivas o enfoques. Una publicación frecuentemente citada sobre conceptos del turismo de salud (Health Care Tourism) es la de Goodrich y Goodrich (1987). Asimismo, los trabajos de Carrera y Bridges (2006) se centran en la definición y estandarización de conceptos sobre la globalización de servicios de salud con un enfoque económico. Por otra parte, Smith y Kelly (2006) publicaron en la revista Tourism Recreation Research, un estudio centrado en la definición de los conceptos de wellness y turismo wellness. Asimismo, Smith y Puczkó publicaron una sinopsis mundial de spas, turismo wellness y turismo médico (2009 y 2014) y su crecimiento (variaciones geográficas y culturales en tradiciones de salud y wellness, globalización de salud y wellness, análisis de tendencias regionales). Recientemente, en 2018, la World Tourism Organisation (UNWTO) y la European Travel Comission (ETC) han publicado, con la participación de Puczkó y Smith, el estudio Exploring Health Tourism.

Connell $(2006,2008,2011$ y 2013) ha centrado sus investigaciones desde una perspectiva de globalización de los servicios de salud y turismo en diferentes países de Asia. Erfurt-Cooper y Cooper (2009) trabajan en fuentes termales naturales (hotsprings) para uso de actividades de ocio, salud y wellness desde una perspectiva no-eurocéntrica. Y en otra publicación Erfurt-Cooper (2014) se centra en los destinos de salud y wellness en Japón. Asimismo, Reismann (2010) investiga sobre el turismo médico en relación con la economía y la política nacional en Asia: Dubái, India, Malasia, Tailandia, Singapur. Este autor defiende la idea de que el comercio de la salud a nivel internacional favorece el bienestar social. Otra publicación de Lunt y Carrera (2010) se dedica al turismo médico en ultramar (cirugía cosmética, dental, trasplante de órganos, tratamientos IVF), además en 2011 Lunt y Carrera, publicaron un estudio en este ámbito sobre tratamientos médicos, páginas web y consumidores. En cuanto a los enfoques, los trabajos de Hall (2011) se han centrado en la interrelación entre el turismo de salud y turismo médico incluyendo turismo wellness, así como en el estudio de los servicios de salud transfronterizos, regulaciones éticas, riesgos potentes individuales y riesgos de la salud pública. Recientemente, 
Voigt y Laing (2013) así como Voigt (2014) han trabajado sobre el desarrollo de destinos de turismo wellness; Voigt y Laing como expertas en wellness y Pforr especializado en turismo sostenible y turismo de salud.

\section{FUNDAMENTOS DE LA DEMANDA DE TURISMO DE SALUD}

Los fundamentos relevantes en los cuales se desarrolla el turismo de salud se integran en los segmentos denominados por Kaspar: sociocultural, económico, tecnológico, político y ecológico, los cuales son considerados por este autor como "sistemas de orden superior" (Kaspar, 1996a:12). Cada uno de estos segmentos confiere distintas motivaciones personales que pueden ser relevantes durante el proceso de selección de un determinado viaje de salud. En este sentido, Kagelmann y Kiefl (2016:23) indican: "La motivación se entiende como la totalidad de los procesos conscientes e inconscientes en un organismo, que no pueden derivarse directamente de estímulos externos, mediante los cuales un comportamiento se pone en movimiento, se mantiene y se dirige hacia el logro de un objetivo específico. Esta idea de las motivaciones personales como un criterio importante para el turismo de salud está efectivamente incorporada en algunas contribuciones científicas recientes al turismo de salud (por ejemplo, DHV 2005/2014:27), pero en general aún es demasiado raro. Es fundamental para la definición de la OMT".

\subsection{Segmento sociocultural}

Uno de los factores que actualmente más influencia proyecta sobre el viaje de salud se refiere al cambio demográfico, en el sentido del hecho constatable del aumento de la esperanza de vida y de las enfermedades que suelen acompañar a ésta, lo cual ocasiona una búsqueda de servicios de salud con el fin de incrementar la calidad de vida. Las nuevas reivindicaciones del grupo de mayores se conocen como better aging (mejor envejecimiento) (BMWi, 2011:10). Lanz-Kaufmann indica: "Desde un punto de vista sociodemográfico, el envejecimiento de la población influye positivamente en la demanda de bienestar. Una mayor esperanza de vida supone que más personas se preocupen por su calidad de vida y, por tanto, por su salud" (2002:67). En los Estados Unidos los adultos mayores se dividen en tres grupos según sus hábitos físicos, espirituales y mentales, son los llamados: "gogo" (activos), "slowgo" (lentos) y "nogo" (no activos), cada uno de los cuales presenta diferentes necesidades (Rulle, 2008:120).

No obstante, no son únicamente el grupo de mayores los impulsores del turismo de salud, también el cambio de valores de vida tiene su impacto, pues los antiguos valores, como la religión, pierden importancia, sin olvidar que, en el mundo ampliamente desarrollado, las necesidades básicas de las personas están abundantemente aseguradas y la sociedad desarrolla crecientes "tendencias narcisistas", si se me permite la expresión, en la búsqueda de "libertad y autodeterminación". También el creciente individualismo influye en la demanda de vacaciones de bienestar. El mayor énfasis puesto en el cumplimiento de las propias necesidades y deseos puede ser particularmente efectivo, junto al mito de la belleza, la juventud y la naturalidad, la necesidad de diversión, variedad y experiencia y la tendencia continua hacia el hedonismo (Kaspar, 1995:5). Así, la abundancia de ocio, o la realización personal, 
se convierten en principios fundamentales (Kagelmann y Kiefl, 2016:9-10). Müller lo indica claramente: "El deseo de un nuevo estilo de vida tiene un gran impacto en la demanda turística y forma un buen "caldo de cultivo" para nuevos patrones de comportamiento turístico" (1997:100). En opinión de Lanz-Kaufmann $(2002$, 66) "el factor social más importante reside en la alta conciencia de sustentación de la salud entre la población", si bien destaca una contradicción típica de nuestro tiempo: la existencia simultánea de "más obesidad y más enfermedades cardiovasculares, resultado del estrés, los malos hábitos alimenticios y la falta de ejercicio". Otros autores como Rulle (2008:12) confirman este factor. Schobersberger (2006:133) dice: "la actitud hacia la salud ha cambiado drásticamente en la última década, lo que definitivamente afectará también al turismo. Por tanto, es necesario seguir el objeto del turismo de salud desde el punto de vista interdisciplinario [...] El principio de la autoresponsabilidad, así como la precaución, influirán fuertemente en las vidas".

Por otra parte, los medios de comunicación apoyan la tendencia sobre la conciencia de la salud personal o la "saluto correctness" (comportamientos saludables correctos) (Rulle, 2008:123). La información sobre la salud y la enfermedad ya no está disponible únicamente a profesionales, sino también a legos (Groß, 2017:25). Por último, pero no por ello menos importante, el creciente nivel educativo de la población facilita la comprensión de procesos complejos, tratamientos específicos de salud e incluso conceptos no occidentales, como por ejemplo el Ayurveda. Smith y Puczkó (2013:79) indican que los medios de comunicación despiertan la curiosidad sobre los viajes de spa y bienestar o estimulan la estancia en un hotel spa, en lugar de en un hotel tradicional, fomentando la intención de acudir a destinos exóticos dotados de instalaciones de atención médica preventiva, como el baño de vapor turco o norteafricano, sento japonés o zonas de meditación budista.

Al mismo tiempo, cierto creciente escepticismo sobre la medicina alopática y una aceptación cada vez mayor de las terapias alternativas (Weiermair y Steinhauser, 2003) inciden en la búsqueda de ofertas vacacionales. El mismo efecto produce la "medicina integrativa", es decir, la medicina complementaria y alternativa, también conocida en el mundo anglosajón como sistema CAM (Complementary and Alternative Medicine) que incluye aplicaciones homeopáticas y naturales de culturas no occidentales, así la medicina tradicional china o el Ayurveda indio. Las terapias basadas en el arte, la música y la danza; terapias de carácter biológico, basadas en alimentos, hierbas medicinales y vitaminas, e incluso prácticas de movimiento corporal, como las técnicas quiroprácticas u osteopáticas o masajes. Además, existen terapias de energía como la terapia de contacto terapéutica: Qui Gong o Reiki (Smith y Puczkó, 2013:62). Muchas de estas prácticas médicas alternativas y complementarias se ofrecen en centros holísticos y de retiro. Asimismo, se incluyen en este apartado las vacaciones de desintoxicación o de nutrición y ayuno (BMWi, 2011:9). Un tipo especial de autorrealización se localiza en las teorías sobre el "renacimiento personal", los "patrones de creencias esotéricos" o en los movimientos de revitalización de culturas ágrafas: geomancia, feng shui o neo-chamanismo (Kagelmann y Kiefl, 2016:12).

Smith y Puczkó (2014:21) alude al concepto de new age (nueva era) consistente en terapias esotéricas llevadas a cabo en retiros, centros de bienestar o festivales. Estos autores indican que las enseñanzas de la new age comenzaron en Inglaterra en la década de 1960 y se popularizaron mundialmente a partir de 1970. La new age, se asocia al movimiento hippie y a los baby boomers. Heelas (1996) afirma que la esencia new age descansa en cierta espiritualidad basada en la noción de un yo interior sagrado. 


\subsection{Segmento económico}

En Europa (y en general en los países altamente desarrollados) en una gran parte de la población, al disponer de abundantes recursos económicos, se produce un fenómeno de descompensación que la literatura especializada identifica como: Cash-rich (rico en efectivo) y time-poor (pobre en tiempo), es decir, se observa que la abundancia de riqueza se asocia al poco tiempo disponible (Smith y Puczkó, 2013:77). Por otra parte, Voigt y Pforr (2014:5) destacan el actual ritmo acelerado de trabajo y vida, de ahí que (Pollock y Williams, 2000) afirmen que el turismo wellness se presenta como un recurso ideal que permite eludir temporalmente el estrés y la sobrecarga laboral. Por otra parte, el aumento del número de aeropuertos y de vuelos baratos, así como la predisposición a trasladarse, que no se limita a una exclusiva capa de la población, facilitan el acceso a los servicios de salud distantes. Hall (2011:7) siguiendo a Milstein y Smith (2006) considera el fenómeno una "dimensión económica del gasto", es decir, una de las cinco dimensiones consideradas por este autor en su clasificación del turismo médico, explicitando las razones de la búsqueda de un servicio más económico que el obtenido en el propio país, o bien según (Eggertson, 2006, MacReady, 2007 en Hall, 2011:6) puedan estar disponibles de manera más oportuna: "dimensión de tiempo y gasto".

\subsection{Segmento político}

Ciertos países disponen de marcos legales que inciden directamente sobre los pacientes en búsqueda de un tratamiento médico específico, generalmente situado en la frontera de la biotecnología. Además, dado que las intervenciones o tratamientos médicos se encuentran sujetos en cada país a regulaciones distintas, resulta claro que las disposiciones legales pueden condicionar positivamente o impedir el desarrollo de determinados tratamientos o procedimientos médicos produciéndose una gama de posibilidades en función de cada legislación nacional, por ejemplo, legislaciones no restrictivas de las prácticas abortivas por razones morales (Illing, 2000:32) o intervenciones quirúrgicas orientadas al cambio de sexo. Otro ejemplo lo encontramos en la terapia celular, de aplicación en ciertas enfermedades neurodegenerativas. Un capítulo importante en este apartado se vincula al deseo de acceder, bajo determinadas circunstancias de infertilidad, a la gestación de la propia descendencia, lo cual estimula el traslado de pacientes hacia países cuya legislación resulta favorable, y que además cuenten con reconocida experiencia y elevados medios científico-técnicos garantes del éxito de la intervención. Es el caso de Alicante con respecto a la reproducción humana asistida. La base de la legislación española sobre técnicas de inseminación artificial se reguló a través de la Ley 14/2006.

\subsection{Segmento tecnológico}

El avance de las tecnologías médicas resulta determinante en el turismo médico. Así, por ejemplo, cierta tecnología médica, antes únicamente aplicada en medicina deportiva, ahora se ofrece también en tratamientos de pacientes comunes, lo cual redunda en el fomento del turismo médico y wellness. Las tecnologías de la información y la comuni- 
cación, TIC, pueden asimismo difundir nuevos modos de capacitación y asesoramiento en el tratamiento del estrés, la nutrición y el deporte. Por consiguiente, existen muchas posibilidades nuevas, especialmente en la conjunción entre la industria de la salud, la tecnología médica y las TIC, que al posibilitar la integración de las tecnologías facilitan la actualización de las ofertas de prevención (BMWi, 2011:12).

\subsection{Segmento ecológico}

Las condiciones ambientales urbanas, cada vez más agresivas con la calidad de vida, inciden en el aumento en la demanda de turismo de salud, por ejemplo, el ruido y la contaminación del aire de las ciudades o las aglomeraciones urbanas refuerzan el deseo de descanso en espacios naturales. No obstante, si por un lado el aumento de la movilidad incide negativamente sobre las condiciones ambientales, dados los efectos perniciosos que el turismo de masas ejerce sobre el medio ambiente, por otro, resulta cada vez más fácil llegar a destinos vacacionales distantes (Lanz-Kaufmann, 2002:67) con el incremento de la consiguiente problemática de la presión antrópica realizada sobre particulares zonas vírgenes o de especial valor natural o cultural.

\section{UN ENFOQUE DESDE LA OFERTA: TIPOS DE ESTABLECIMIENTOS EN EL TURISMO DE SALUD}

La literatura especializada identifica quince tipos de establecimientos receptores, los cuales se integran a efectos prácticos en cuatro modalidades: "turismo médico", "turismo

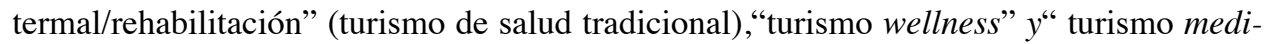
cal wellness"(turismo de salud moderno).

\subsection{Turismo médico}

Según la Organización Mundial del Turismo, "El turismo médico es un tipo de actividad turística que implica el uso perentorio de recursos y servicios de curación médica (tanto invasivos como no invasivos). Esto puede incluir diagnóstico, tratamiento y cura, prevención y rehabilitación" (2018:12). Se realiza en hospitales y clínicas y sus derivados. En este caso, el paciente viaja a la consulta de un médico de reconocido prestigio, o bien a un establecimiento hospitalario o clínico dotado de la especialidad buscada. Existen publicaciones especializadas en las cuales encontramos distintos términos utilizados para expresar el fenómeno de turismo médico, así: "turismo de paciente" (Rulle, 2008:41); "turismo clínico", "turismo de enfermedad" (Reismann, 2010:93-94); o "viaje médico"(Kagelmann y Kiefl, 2016:168; Woodman, 2008); e incluso "medical holidays", literalmente, "vacaciones medicinales". Otros términos aparecen en el ámbito de la economía, como:“cross-bordertrade in health services" (servicios de salud transfronterizos) en Bünten (2011:42ss) o "transnational medical care" (atención médica transnacional) en Sobo (2009). Términos semejantes se encuentran en estudios de Sociología general o Sociología médica. En la literatura anglosajona destacan los trabajos de Connell, quien considera el turismo médico, "aplicable en los casos en que la mejora de la salud es un elemento primordial dentro de 
la planificación de las vacaciones [...] y donde en tales preparativos se consideran ciertas circunstancias drásticas (pero también exámenes médicos y chequeos rutinarios) en lugar de una práctica más relajada del turismo de salud y wellness, que incluyan actividades saludables tales como senderismo y paseos por el bosque" (2011:7). Este autor considera el turismo médico una categoría situada al mismo nivel que el turismo de salud y con límites permeables entre ambas. Además, cuestiona el valor mínimo tradicional de consideración turística de permanencia en destino de una pernoctación, pues resalta que actualmente es posible realizar, por ejemplo, tratamientos de ortodoncia complejos en un aeropuerto en el mismo día mediante el procedimiento fly-in fly-outy entiende que tales desplazamientos son turismo médico (2011:5). Esta concepción amplia también se encuentra en Cohen (2008:227) cuando clasifica lo que llama "viajero medicinal" (medical traveller) en cuatro grupos: 1. "turista medicado" (medicated tourist) que recibe tratamiento por problemas de salud sobrevenidos durante las vacaciones en el extranjero; 2. "turista medicado propiamente" (medicated tourist proper) aquellos que visitan un país para recibir un tratamiento médico, o bien que deciden la intervención médica una vez se encuentran en el país de destino; 3. "paciente de vacaciones" (vacationing patient) define así a quienes acuden al destino principalmente para un tratamiento médico, pero además, realizan un uso accesorio de oportunidades de vacaciones, por lo general durante el período de convalecencia; y 4. "mero paciente" (mere patient) que llega a su destino exclusivamente para recibir tratamiento médico, y no hace uso de vacaciones oportunas.

Una acotación metodológica a esta amplia perspectiva, lo constituye el estudio de Ehrbeck et al. (2008:3) quienes consideran que deben excluirse los residentes extranjeros en la consideración de medical traveller (viajero medicinal), pues si los pacientes internacionales que reciben una intervención médica representan la totalidad, debemos no considerar de esta totalidad el porcentaje que represente a los residentes extranjeros (que han obtenido una intervención médica en el país donde residen), así como el porcentaje de los casos atendidos por vía de urgencia. El neto restante representará, según estos autores, la atención ofrecida al "viajero medicinal".

\subsection{Turismo termal / rehabilitación}

El turismo termal tiene en Europa una larga tradición, de tal modo que algunos autores lo identifican como turismo de salud tradicional (Rulle et al. 2010:7) y lo consideran una subcategoría de turismo de salud integrado por "la totalidad de las relaciones y los fenómenos resultantes de la estancia de personas con el propósito de restaurar el organismo humano a través de una cura y los viajes relacionados desde y hacia el lugar de origen" (Kaspar y Fehrlin, 1984:24). El destino clásico del turismo termal y de rehabilitación lo constituye el balneario, allí tienen lugar tratamientos terapéuticos con medios y métodos propios de los baños medicinales característicos de la balneoterapia.

Según Rulle, las razones por las cuales los huéspedes de los balnearios se deciden a realizar el viaje de turismo de salud tradicional son: 1 . prevención de enfermedades, 2. tratamientos termales de enfermedades crónicas y padecimientos, y 3. rehabilitación después de accidentes y enfermedades (2008:21). De este modo el viaje de turismo termal y de rehabilitación incluye sobre todo la prevención secundaria (detección y tratamiento 
temprano) y prevención terciaria (prevenir la progresión de una enfermedad) (Lanz-Kaufmann, 2002:49). En los últimos años las ofertas de baños termales se han orientado en mayor grado a personas sanas, por lo cual se observa una tendencia hacia el medical wellness o wellness (Rulle et al., 2010:7).

\subsection{Turismo wellness}

No está claro el origen del término wellness. Según la definición recogida por Lanz-Kaufmann (2002: 19) del diccionario Oxford (1971:3738), el término wellness se deriva del inglés antiguo Wealnesse, que era una expresión de salud y bienestar. El diccionario cita una monografía del año 1654 donde aparece: “[...]blessedGod [...] for my daughter "swealnesse". Sin embargo, parece ser que Dunn $(1959,1961)$ fue quien primero utilizó el término wellness obtenido de las palabras: wellbeing y fitness y formó un acróstico para referirse a un conjunto de servicios utilizados con el fin de "contrarrestar previamente enfermedades mediante estilos de vida conscientes y conformes a reforzar los factores de la protección natural física", alcanzando el individuo un estado óptimo que él llama high-level wellness. Dunn en Lanz-Kaufmann (2002:19) promovió la unidad de cuerpo, alma y espíritu en dependencia de su entorno. Según Illing (2009), posiblemente Dunn se apoyó para la elaboración de su concepto wellness en la definición de salud redactada por la Organización Mundial de la Salud (OMS) en el año 1947: "a state of complete physical, mental and social wellbeing and not merely the absence of disease of infirmity". La definición de Dunn fue ampliada por Ardell en 1977. Según Ardell, high level wellness es consecuencia de la responsabilidad personal (self-responsability), la conciencia de la nutrición (nutritional awareness), el fitness corporal (physical fitness), el control de la presión psíquica (stress management) y la sensibilidad hacia el medioambiente (environmental sensitivity). Posteriormente, en una segunda edición ampliada, este autor incluyó normas y valores sociales, así como aspectos éticos (Ardell, 1986:324ss).

Lanz-Kaufmann (2002:22) al identificar la "armonía" como expresión máxima de salud según la definición de la OMS, reformuló el concepto wellness basado hasta entonces en cuatro elementos: 1. fitness/cuidado corporal, 2. nutrición saludable, 3. relajación y 4. actividad espiritual/formación; e incorporó la idea de que para alcanzar wellness, la persona debe aportar algo de sí misma, es decir, debe asumir cierta responsabilidad propia. Además, considera esencial las relaciones sociales y la sensibilidad hacia el medioambiente. Asimismo, en vez del término "conciencia de nutrición" empleado por Ardell, Lanz-Kaufmann precisa el término "nutrición saludable". Además, Lanz-Kaufmann basándose en la "conciencia de estrés" y el "vencimiento de estrés" de Haug (1991:428), introdujo el término más finalista de "relajación", explicitando la "actividad espiritual/formación" de Opaschowski (1987:34). Así como la sensibilidad hacia el medioambiente natural y social en el sentido de Ardell. Por consiguiente, Lanz-Kaufmann (2002:22) define wellness: "Un estado de salud de armonía de cuerpo, mente y alma. Los elementos esenciales son la responsabilidad personal, el estado físico y la higiene personal, la alimentación saludable, la relajación, la actividad / formación, así como las relaciones sociales y la sensibilidad ambiental". 
Por otra parte, el turismo wellness fue definido en un trabajo conjunto realizado por Müller y Lanz-Kaufmann (2001:7) apoyándose en la definición de turismo de salud de Kaspar (1996b:56): "Turismo wellness abarca un viaje y estancia de personas con el motivo principal de mantener o fomentar su salud. La estancia se realiza en un hotel especializado, con la competencia profesional adecuada y atención individualizada, en el cual se ofrecen un conjunto amplio de servicios que incluyen los siguientes elementos: fitness/cuidado corporal, nutrición saludable, relajación y actividad espiritual/formación”. Con sus trabajos, Müller y Lanz-Kaufmann, ofrecieron una orientación científica en el estudio del turismo wellness germano parlante.

Recientemente, la Organización Mundial de Turismo (OMT/UNWTO) ha considerado el concepto turismo wellness: "un tipo de actividad turística que tiene como objetivo mejorar y equilibrar todos los dominios principales de la vida humana, incluidos los físicos, mentales, emocionales, ocupacionales, intelectuales y espirituales. La motivación principal para el turista de bienestar es participar en actividades preventivas, proactivas y que mejoren el estilo de vida, tales como ejercicios físicos, alimentación saludable, relajación, mimos y tratamientos curativos" (UNWTO, 2018:12).

\subsection{El turismo medical wellness}

El turismo medical wellness se originó en los Estados Unidos, dando prioridad en su práctica a los aspectos médicos sobre los termales (Rulle et al., 2010:10). Se puede considerar una forma modernizada del turismo termal tradicional, y se sitúa como concepto mixto entre turismo médico y turismo wellness, pues según la organización estadounidense Medical Wellness Association (MWA, 2019):“El medical wellness brinda atención médica en la cual se consideran las múltiples influencias en la salud de una persona". Asimismo, el Instituto Europeo de Wellness (EWI, 2019), indica que: "medical wellness se desarrolló a partir del amplio movimiento wellness que fomenta la salud por métodos de prevención primaria y tratamientos de reconocidos métodos terapéuticos naturistas. De este modo medical wellness se vincula a los mercados de la medicina y la industria de wellness y constituye un puente entre el bienestar subjetivo, la prevención y la salud tutelada por un médico". También la Asociación Wellness Alemana (DWV, 2019), sugiere que el término medical wellness puede ser usado para integrar los conceptos de salud y wellness en el sentido que existe un programa supervisado por un médico, lo cual mejora la idea wellness. Medical wellness implica la realización de cambios específicos en el estilo de vida, llamados por la DWV, Lebensstil-Medizin (Medicina del estilo de vida): "Medical wellness es adecuado para personas que tienen problemas de salud o enfermedades ya manifiestas, ocasionadas por su estilo de vida. Como regla general, se trata de enfermedades crónicas, que se presuponen en el término común de enfermedades de la civilización moderna. Con la ayuda del concepto Lebensstil-Medizin, las enfermedades y las afecciones se pueden tratar de manera efectiva. Pero el actor principal no es ya un facultativo, sino el paciente mismo, que hace correcciones sustanciales y duraderas en su estilo de vida. De modo que medical wellness no es un tratamiento médico, sino una medicina conductual. El objetivo está centrado en facilitar el cambio y el mantenimiento de un estilo de vida saludable". Illing puntualiza: "En contraste con el término wellness, medical wellness, enfatiza el 
carácter médico. La atención se centra no sólo en la prevención de enfermedades, sino también en la estabilización de la propia calidad de vida, por ejemplo, en una enfermedad crónica" (2009:10).

\section{METODOLOGÍA DE TRABAJO Y FUENTES}

Tras la sistematización de la literatura sobre el tema y de sus principales enfoques, se ha llevado a cabo una recopilación de datos secundarios sobre turismo de salud desde 2016 hasta 2019 a partir de distintas fuentes, y mediante la selección de los establecimientos objeto de estudio en el ámbito de la provincia de Alicante basados en búsquedas de páginas web. La selección de establecimientos médicos (hospitales y centros sanitarios) fue realizada atendiendo a los siguientes criterios: 1. de los 25 hospitales registrados en el Catálogo de Hospitales de la Diputación de Alicante: (https//:www.documentacion. diputacionalicante.es/pr_hospital.asp, el día 08 de noviembre 2019) únicamente han sido seleccionados los hospitales de titularidad privada, dado que los hospitales de titularidad pública no compiten en el mercado de turismo de salud. 2. Con respecto a las cuatro mil quinientos noventa y ocho centros sanitarios ubicados en la provincia de Alicante y registrados por la Consellería de Sanidad Universal y Salud Pública de la Generalidad Valenciana: (https://itsiscv.san.gva.es/roscent/mostrarCentros) fueron incluidas todas aquellas clínicas con al menos un rasgo turístico en la oferta (Kaspar, 1996a:86) accesibles a través de buscadores especializados en turismo médico como:

\begin{tabular}{|l|l|l|}
\hline www.whatclinic.com & www.fertilityclinicsabroad.com & www.imtj.com \\
\hline www.medicaltourism.review.com & www.medigo.com & www.ovu.com \\
\hline www.mediterranean-healthcare.com & www.mymeditravel.com & www.treatmentabroad.com \\
\hline www.health-tourism.com & www.reproduccionasistida.org & www.medicaltourism.com \\
\hline
\end{tabular}

Con respecto a los demás establecimientos, tales como hoteles, resorts y retiros, se han considerado aquellos categorizados por la Agencia Valenciana de Turismo en el rango de cuatro y cinco estrellas, ya que las ofertas de los hoteles spa y hoteles wellness se encuentran sobre todo en las categorías superiores, en total ciento dos hoteles. Además, se analizó la oferta de los restantes tipos de establecimientos sea con servicios médicos de cuidado y terapias especiales (según la argumentación de Kaspar, 1996a:86) más las once categorías de Voigt (2014) ya indicadas, con las cuales se puede identificar el turismo wellness. Se ha tenido en cuenta su posible colaboración con clínicas u hospitales.

En el caso de los establecimientos de menor rango que compiten en el turismo de salud, se han realizando búsquedas sistemáticas mediante google por tipología hotelera internacional de establecimiento (trece tipos: therapeutic lifestyle retreat, wellspital, balneario hotel, med hotel, Medical spa, clínica de rehabilitación, medical wellness hotel, care hotel, patient hotel, beauty spa hotel/resort, lifestyle resort, spiritual retreat, y wellness hotel). Fueron consultadas las siguientes plataformas especializadas: 


\begin{tabular}{|l|l|l|}
\hline www.spa-in-spain.com & www.balneariosyspa.com & www.balnearios.org \\
\hline www.bookyogaretreats.com & www.bookretreats.com & www.retreatnetwork.com \\
\hline www.revivaretreats.com & www.yogabreaks.org.uk & www.bookretreats.com - \\
\hline www.retreat.guru & www.tripadvisor.com & www.nolimits.life/es \\
\hline www.yogabreaks.org.uk & www.responsibletravel.com & www.bookdetoxretreats.com \\
\hline
\end{tabular}

Cada uno de los establecimientos se han definido mediante su oferta y se han clasificado por tipología. Seguidamente se ha procedido a su agrupación atendiendo a las cuatro modalidades del turismo de salud: "turismo médico", "turismo termal / rehabilitación", "turismo medical wellness" y "turismo wellness".

Los diferentes tipos de establecimientos ofertantes fueron evaluados y considerados desde el modelo teórico del turismo de salud como sistema propuesto por Kaspar (1996a:11-13). En este modelo Kaspar identifica dos subsistemas, uno denominado "subsistema sujeto de turismo" y otro denominado "subsistemas institucionales objeto de turismo", integrado a su vez por tres subsistemas: "lugar del turismo", "empresas del turismo" y "organizaciones del turismo". Sobre estos dos subsistemas "sujeto" y "objeto" incide lo que él denomina "sistemas de orden superior" y que identifica en los entornos: económico, social, tecnológico, político y ecológico. Estos entornos configuran y delimitan los fundamentos del turismo de salud, razón por la cual en el presente trabajo se han referido cinco tipos de fundamentos principales: sociocultural, económico, político, tecnológico y ecológico. Estos fundamentos promueven y condicionan la oferta de servicios generada por el subsistema institucional "empresas del turismo" integrado en el "subsistema institucional objeto del turismo".

\section{ANÁlisis EMPÍRICO. APLICACIÓN AL SISTEMA DE TURISMO DE SALUD DE LA PROVINCIA DE ALICANTE}

Una vez expuesto los fundamentos teórico-conceptuales, los rasgos fundamentales de los segmentos de demanda y la tipología de establecimientos; el estudio se centra en su aplicación a la provincia de Alicante con el fin de conocer cómo se ha configurado el sistema de turismo de salud y hacia qué tipo de demanda se ha orientado su oferta desde que inicia su constitución como tal sistema específico, a finales de la década de los ochenta del siglo XX. No obstante, cabe hacer mención a que los orígenes del turismo de salud en la provincia de Alicante se remontan al último tercio del siglo XIX, con el auge de la talasoterapia asociada a los balnearios marítimos, y a los intentos de promoción de la ciudad de Alicante como destino turístico de invierno, según la idea de salud de la época y el concepto de estación invernal, ambos intrínsecos a la calidad climática. Estos aspectos han sido ampliamente estudiados en la bibliografía especializada existente referida a los orígenes del turismo alicantino (entre otros autores, Vera,1987; Olcina y Miró, 2016).

En la actualidad, el turismo de salud de la provincia de Alicante se desarrolla en cuatro modalidades: "turismo médico", "turismo termal / rehabilitación", "turismo wellness" y "turismo medical wellness" (véase cuadro 1). Sin embargo, en estas modalidades dominan dos modelos que cabría considerar asimismo como subsistemas: uno regido por el 
turismo médico y geográficamente polarizado en ciudades y grandes destinos turísticos, y otro regido por el turismo de rehabilitación, medical wellness y wellnes, y que sigue una distribución territorial más repartida.

\section{Cuadro 1 \\ IMPLANTACIÓN DE ESTABLECIMIENTOS SEGÚN MODALIDAD}

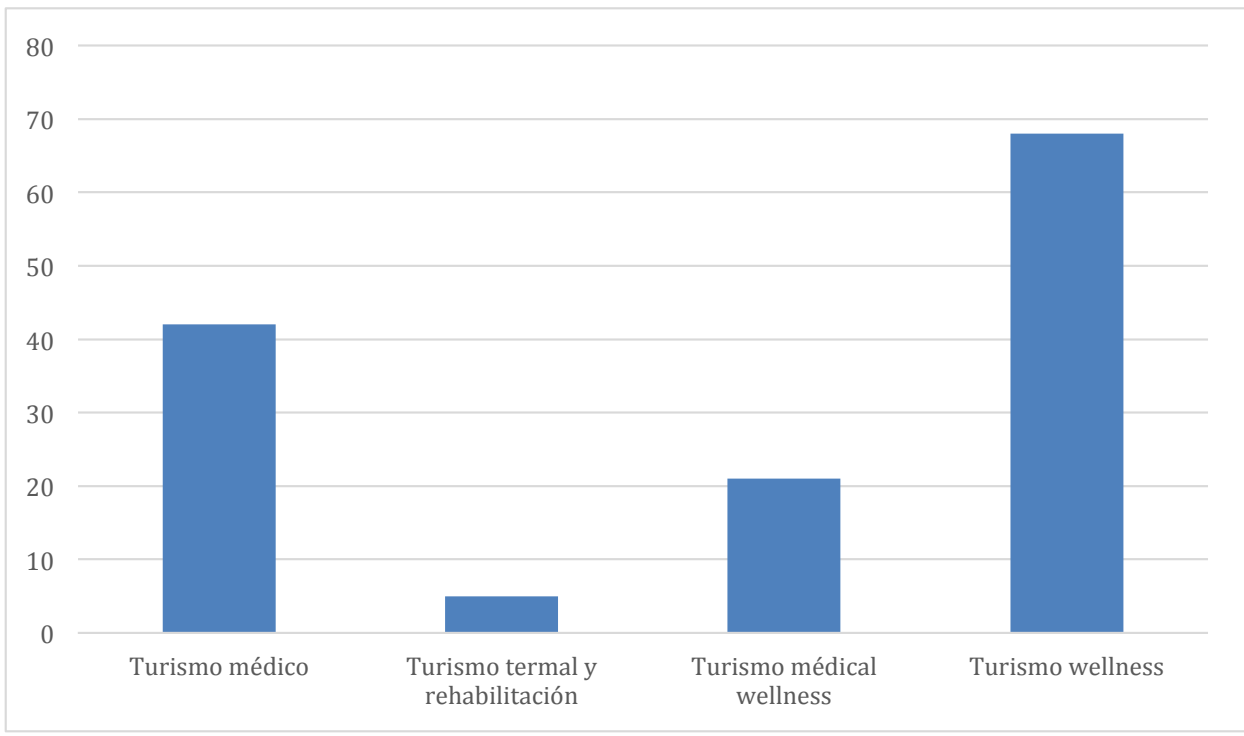

Fuente: Elaboración propia.

\subsection{Turismo médico: su polarización en ciudades y grandes destinos turísticos}

En la provincia de Alicante existen actualmente veinticinco hospitales (trece públicos y doce privados) de los cuales siete de titularidad privada manifiestan actividad en el turismo médico: tres en Alicante ciudad, dos en Benidorm, uno en Elche y uno en Torrevieja. Estos cuatro núcleos urbanos constituyen por sí mismos, es decir, al margen del turismo de salud, uno de los grandes destinos turísticos de la provincia, y además, dos de estos destinos: Benidorm y Torrevieja, cuentan con una elevada población de residentes extranjeros. Las infraestructuras urbanas y turísticas de estos destinos han fomentado el establecimiento de los centros médicos, hospitales y clínicas, cuya actividad se centra en el turismo de salud, pero no únicamente, pues se ha de considerar a este respecto la benéfica influencia ejercida de las dos universidades alicantinas sobre el turismo médico, con sus dos parques científicos, los institutos de investigación existentes, como el de Neurociencias, el de Biología Molecular y Celular o el Instituto de Bioingeniería, además de la labor investigadora que realizan los propios hospitales y clínicas.

Los siete hospitales activos en el turismo médico se distinguen por la presencia en su oferta de elementos turísticos en su página web: ayuda en el desplazamiento, servicios de 
recepción en el aeropuerto, reserva de hoteles, uso de mediador especializado, servicios de traducción/ interpretación, regularización de visados, etc. Cinco de los siete hospitales ofertan la especialidad de fertilización humana asistida. Además de esta especialidad también se ofrece cirugía plástica/estética en siete hospitales, en dos oftalmología, odontología y cardiología en cuatro hospitales, y en uno la especialidad de oncología, en estos centros sanitarios la atención médica se combina con servicios turísticos (véase cuadro 2). Dos hospitales trabajan según el sistema de la Joint Commission International. Conviene destacar que la JCI está considerada la acreditación internacional de mayor reconocimiento en hospitales. De los siete hospitales actualmente operativos en turismo de salud, tres son miembros del cluster denominado Mediterranean Health Care.

De los casi cuatro mil seiscientos centros sanitarios pertinentes, solo treinta y cinco exhiben rasgos de turismo médico en su página web. En la especialidad de la fertilización humana asistida actúan trece clínicas (consideradas como unidades de atención en su localidad). Dos de las ofertantes tienen tres sedes cada una en varios lugares de la provincia de Alicante, y una clínica incluso tiene cinco centros en distintos puntos de la provincia. Además, se constata según especialidad: siete en cirugía plástica/estética, ocho clínicas en odontología, siete en oftalmología (véase cuadro 2).

\section{Cuadro 2 \\ ESPECIALIDADES DE TURISMO MÉDICO Y NÚMERO DE CENTROS EN CADA ESPECIALIDAD}

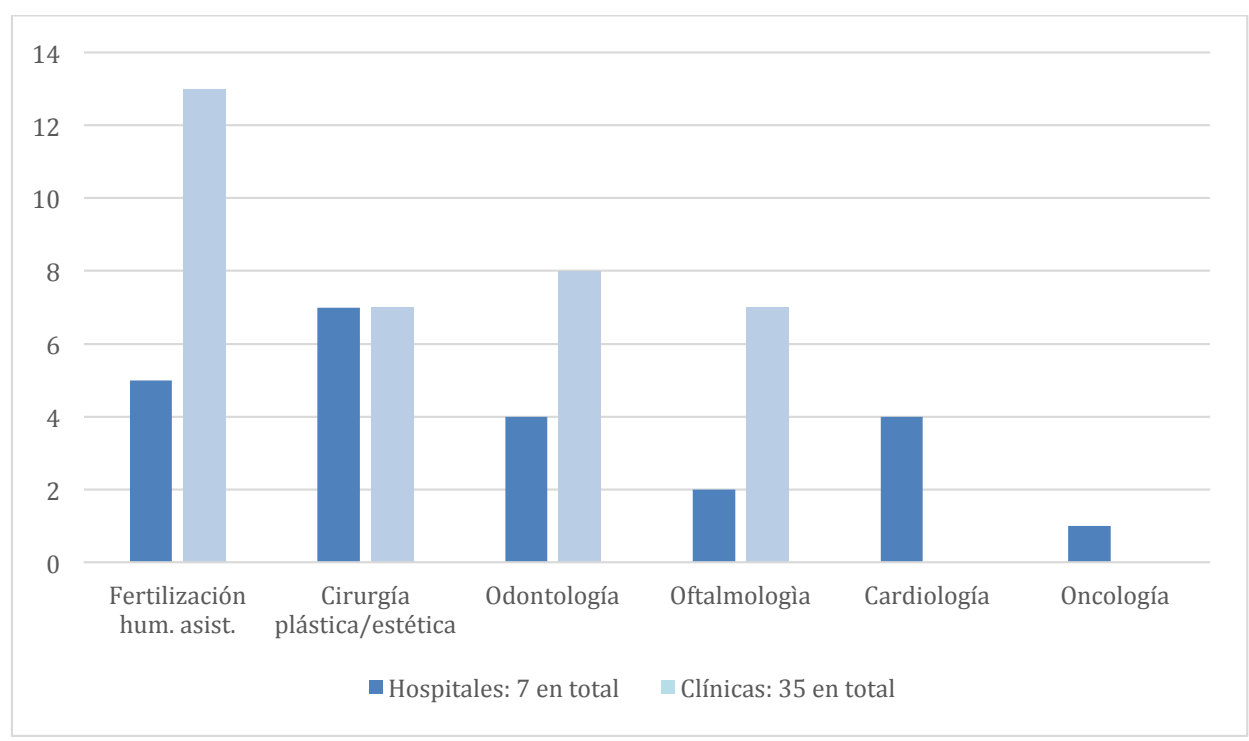

Fuente: Elaboración propia. 


\subsection{Turismo termal / rehabilitación, turismo wellness y turismo medical wellness: una distribución territorial más repartida}

Si se considera que la población de residentes extranjeros en la provincia de Alicante es mayor que la población de origen nacional en los municipios de Alfas del Pí, Calpe, Jávea, Rojales, Teulada y Torrevieja, se podrá apreciar con mayor precisión el modelo de implantación en la provincia de estas tres modalidades, pues esta población residente actúa de potencial consumidor de las ofertas de los establecimientos locales, además de colaborar en la difusión de su imagen turística. Cabe mencionar a este respecto, y a modo de ejemplo, la existencia y actuación de pequeños y medianos establecimientos tipo retreat y resort que ofertan sus servicios en la Marina alta y baja, comarcas de belleza paisajística. En las dos comarcas de la Marina son mayoritarios los residentes de origen comunitario, mientras que la comarca de la Vega Baja acoge a residentes extranjeros no comunitarios, en esta comarca destaca Torrevieja con una población de residentes extranjeros no comunitarios de más del $70 \%$. Con respecto al resto de poblaciones cabe afirmar que, en general, los municipios costeros son los que tienen un mayor porcentaje de población extranjera y por consiguiente resultan partícipes activos en el turismo de salud. E inversamente, los municipios de la comarca del Alto Vinalopó, carecen de significación en esta actividad. Algo semejante sucede en la comarca del Alcoià, que con la excepción de un establecimiento tipo lifestyle resort que se encuentra en Bañeres, el resto de municipios de esta comarca no participan en el turismo de salud.

Las tres modalidades de turismo de salud se encuentran bien implantadas en la provincia de Alicante, dado que, de los trece tipos de establecimientos identificados u operantes, once de ellos cuentan como mínimo con un establecimiento. Cabe señalar, si consideramos el tamaño de los establecimientos, otro rasgo de estas tres modalidades, pues el turismo wellness y medical wellness se implanta en los destinos turísticos con ofertas de salud que requieren grandes inversiones: spa hotel, wellness hotel, medical wellness hotel y medical spa hotel, lo cual lleva implícita una atención ciertamente alejada de la personalización y especificación requerida en otro tipo de ofertas de estas modalidades, ofertas diseñadas individualmente y que se practican en pequeños establecimientos, la mayoría de los cuales se pueden encontrar en el interior de la provincia, así como en las ciudades costeras. Entre estos se consideran: spiritual retreat, therapeutic lifestyle retreat y lifestyle resort. En suma, la modalidad de turismo wellness tiene una implantación completa de todos sus establecimientos tipo en la provincia como se puede apreciar en el siguiente cuadro 3.

Por otra parte, las modalidades de turismo wellness y medical wellness, ofrecen servicios y productos en los fundamentos o "sistemas de orden superior sociocultural" y "ecológico". Medical wellness atiende sin la concurrencia de la modalidad wellness los servicios en "desintoxicación" y "new age". La modalidad wellness mantiene una actuación dominante considerando el número total de establecimientos y centra su atención en la provincia de Alicante mayoritariamente en los servicios de "belleza", "medicina complementaria y alternativa" y "nutrición y dieta saludable"; mientras que medical wellnesses mayoritario en "betteraging", "saluto correctness", "desintoxicación" y "new age" (véase el cuadro 4). 


\section{Cuadro 3}

MODALIDAD TERMAL / REHABILITACIÓN; MEDICAL WELLNESS Y WELLNESS Y NÚMERO ESTABLECIMIENTOS

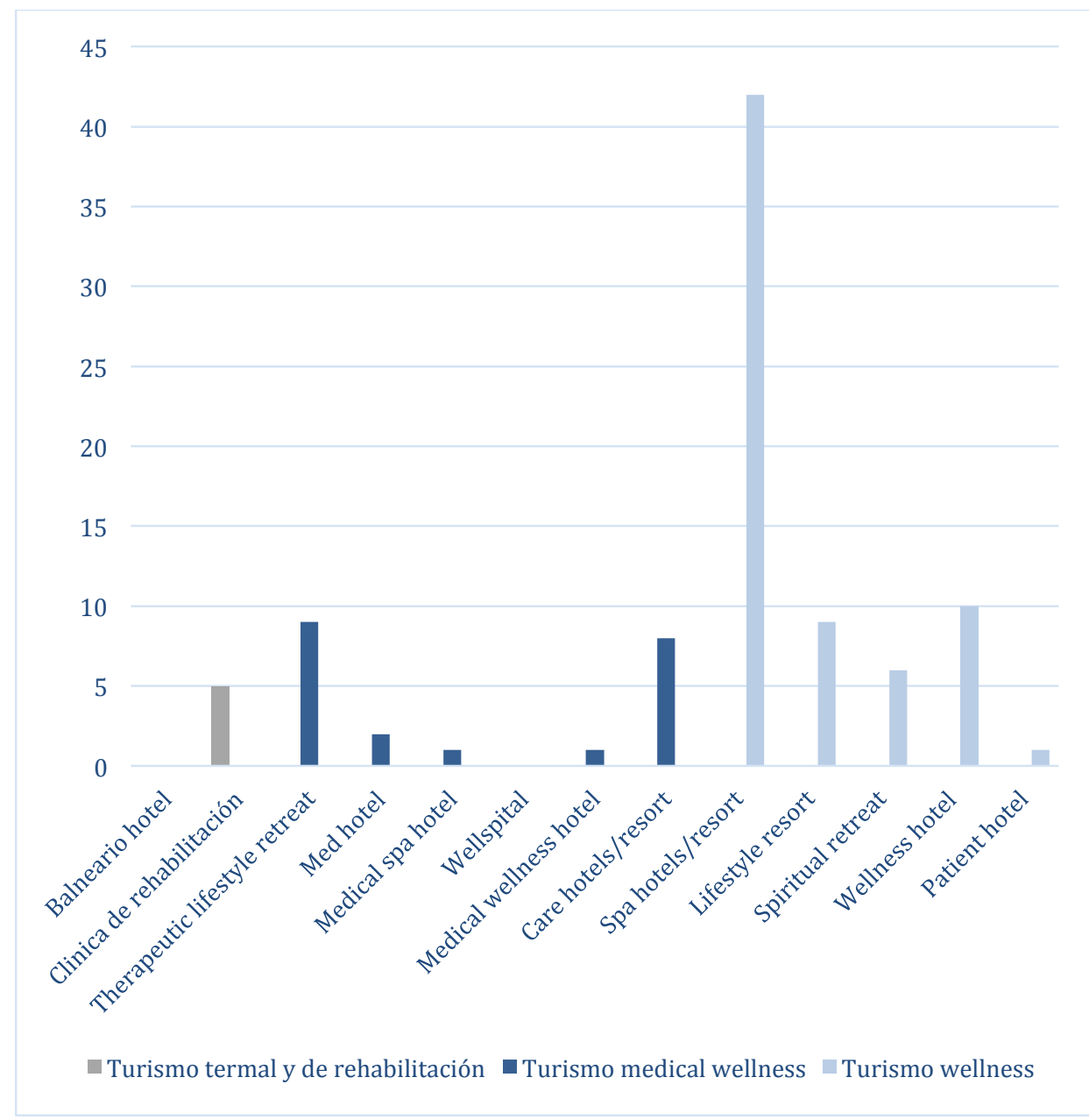

Fuente: Elaboración propia.

Ahora bien, considerando estas dos modalidades cualitativamente, es decir, desde la dedicación al fundamento atendido y en relación al número total de establecimientos de cada modalidad (medical wellness: veintiuno; wellness: sesenta y ocho, véase el cuadro 1) se observa mayor coherencia y concentración en la modalidad medical wellness, pues el número de establecimientos que ofrecen atención en cada fundamento es mayor que la dedicación ofrecida en wellness, por ejemplo, en el segmento "nutrición y dieta saludable" el $86 \%$ de los establecimientos medical wellness ofrecen nutrición y dieta saludable frente 
al $37 \%$ en wellness. Lo cual quiere decir que medical wellness mantiene una mayor especialización sobre la gama de los fundamentos que la modalidad wellness (véase el cuadro 5).

Por último, y con el fin de evitar una excesiva descripción, únicamente se deja constancia de los tipos de establecimientos inexistentes en la provincia según su modalidad. En la modalidad segunda de turismo termal, se constata la inexistencia de establecimientos de este tipo, si bien los hubo hasta el primer tercio del siglo XX en Aigües (en época histórica Aguas de Busot). Actualmente en la provincia, la rehabilitación también incluye la desintoxicación. La modalidad tercera, turismo medical wellness, tampoco dispone de algún establecimiento tipo wellspital, es decir en la provincia de Alicante no existen centros clínicos u hospitalarios que ofrezcan al mismo tiempo el concepto wellness.

\section{Cuadro 4}

\section{FUNDAMENTOS SOCIO-CULTURALES Y ECOLÓGICOS ATENDIDOS POR} MODALIDAD MEDICAL WELLNESS Y WELLNESS (VISIÓN CUANTITATIVA)

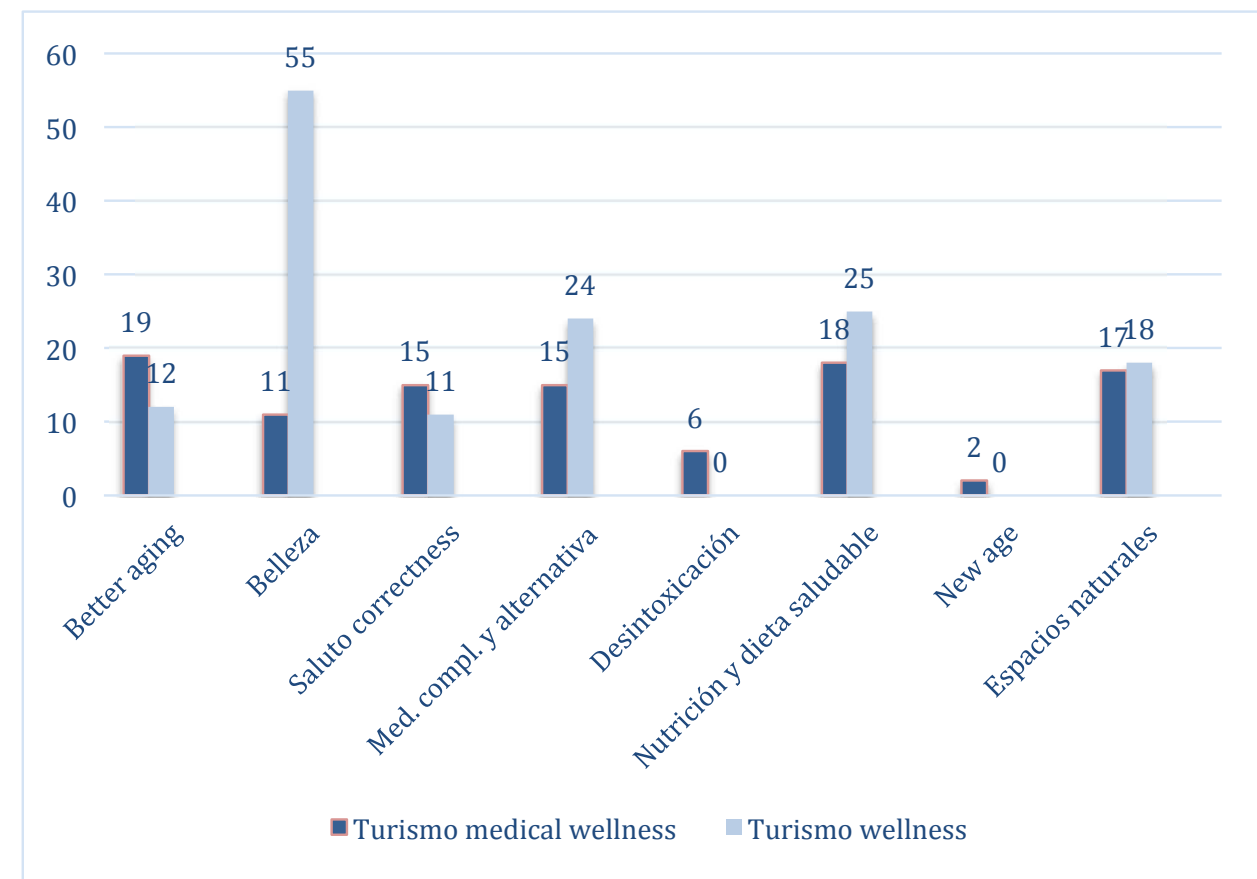

Fuente: Elaboración propia. 


\section{Cuadro 5 \\ FUNDAMENTOS SOCIO-CULTURALES Y ECOLÓGICOS ATENDIDOS POR MODALIDAD MEDICAL WELLNESS Y WELLNESS (VISIÓN CUALITATIVA)}

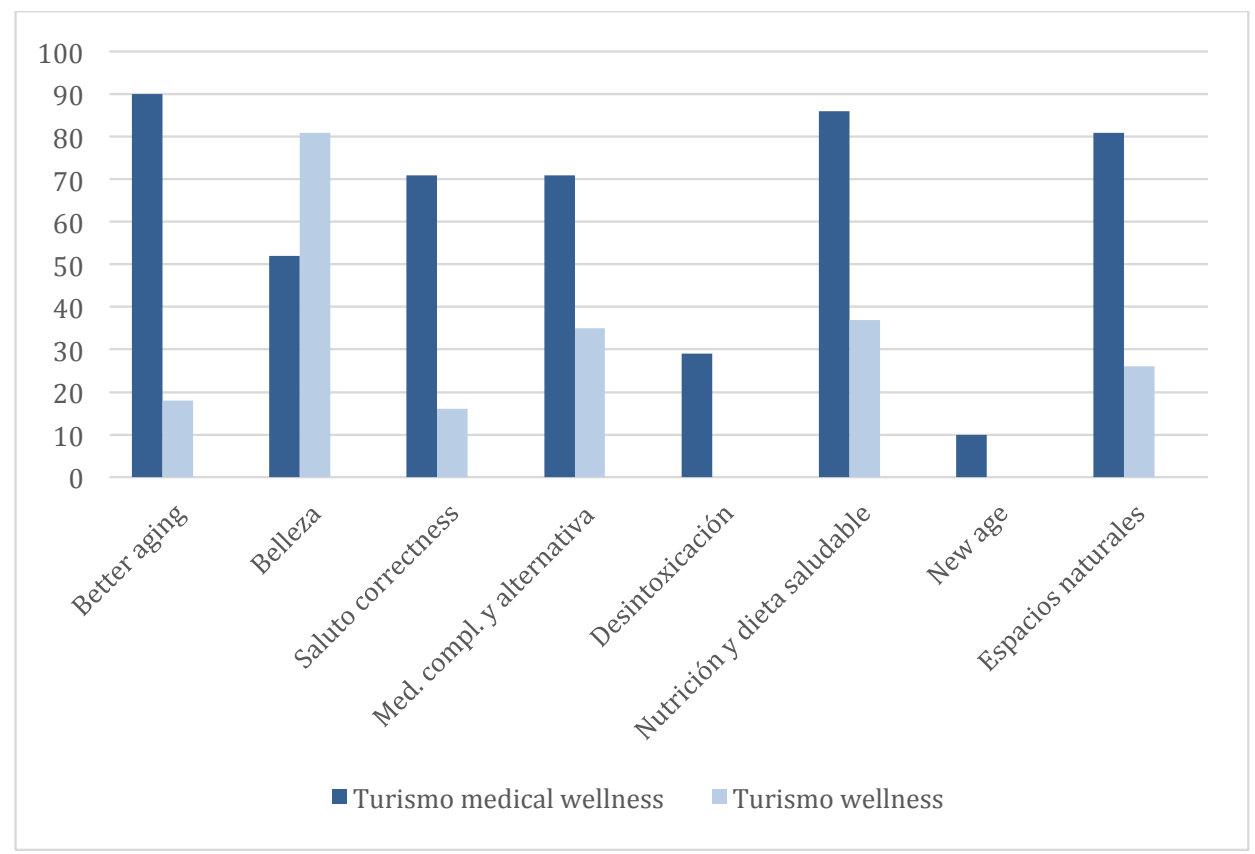

Fuente: Elaboración propia.

\section{DISCUSIÓN}

El turismo de salud, como concepto complejo, es en sí mismo un sistema orgánico y por tanto interdependiente en sus partes y receptivo a las influencias sociales. En él actúa un gran número de establecimientos distintos en cuatro modalidades que también se encuentran alejadas de consideración simple, pues cabe en ellas heterogeneidad. El turismo de salud genera un amplio conjunto de servicios altamente elaborados, de ahí que al acometer su análisis sea del todo pertinente adoptar una perspectiva multidisciplinaria. La teoría de sistemas deviene por consiguiente en herramienta útil para su análisis. La mayoría de los especialistas en la materia aplican la teoría de sistemas al turismo en general, si bien Kaspar al aplicarlo a lo que denomina "establecimientos para sanar", amplía la perspectiva al turismo de salud. Kaspar, además, considera el entorno como un sistema que denomina genéricamente "de orden superior", compuesto a su vez de cinco sistemas. En estos sistemas tiene lugar la decantación de la demanda, la cual fundamenta la elaboración de la oferta. El "sistema de orden superior sociocultural" se encuentra sustentado, en lo que respecta a aquello que es objeto de nuestra atención, por el hecho del aumento de la esperanza de vida y en la alta conciencia del mantenimiento de la salud; estos hechos 
socioculturales son la génesis de conceptos como: "better aging", "auto responsabilidad", "saluto correctness", "terapias alternativas", "nutrición saludable", "new age", etc. El "sistema de orden superior económico" hace posible la necesaria ausencia temporal de los ámbitos urbanos, frecuentemente saturados e incluso nocivos. El "sistema de orden superior político" ofrece cobertura legal a determinadas prácticas médicas. El "ecológico" otorga valor a los espacios naturales y sostenibles y, en fin, el "técnico" cohesiona el conjunto, pues resulta obvio que, sin una integración de tecnología, procesos, conocimientos e infraestructuras, no sería posible el turismo de salud.

Ante esto cabe preguntarse por el sentido del turismo de salud en la provincia de Alicante. Tres tipos de argumentos pueden aportarse desde nuestra perspectiva: uno final, otro estructural y un tercero, motivacional.

Si se considera desde la perspectiva evolutiva reciente del turismo en Alicante, se observa cómo los distintos acontecimientos que jalonan su proceso de configuración han estado dirigidos por su alcance y adecuación. Así, desde aquel pionero turismo de salud talasoterápico y termalista, se han ido sucediendo distintas fases hasta llegar a la situación actual. Por tanto, cabe considerar el turismo de salud en la provincia de Alicante como consecuencia final de los previos acontecimientos de su evolución turística, los cuales fueron preparando su implantación y desarrollo. No resulta pertinente especificar aquí, por conocidas, las fases del desarrollo turístico alicantino ya que una visión de conjunto puede ser consultada por ejemplo en el número 66 de la revista Canelobre, monográfico dedicado al turismo en Alicante y la Costa Blanca (VV.AA., 2016), por lo que ahora únicamente cabe afirmar lo dicho: que el sentido final del turismo de salud de la provincia de Alicante ha venido determinado por su evolución reciente.

Desde una perspectiva estructural, es decir, desde la relación entre la modalidad analizada y el sistema turístico en general, el turismo de salud en la provincia de Alicante surge con un sentido claramente renovador, pues permite nuevos cauces de actuación en un destino turístico maduro o altamente desarrollado, como es el caso de la actividad turística alicantina, dada su amplia actuación y trayectoria, tanto sectorial como temporal. Por otra parte, el turismo de salud tiene la virtud de favorecer la superación de un grave problema del turismo alicantino: la fuerte estacionalidad que tradicionalmente le ha caracterizado y, además, mantiene un carácter de sostenibilidad perfectamente compatible, al menos en teoría, con otros valores actuales como son la protección del medioambiente. Cabe recordar, por último, que el carácter inherente de oxímoron (Bünten, 2011:10), es decir, la conjunción de términos contrarios con efecto paradójico, que se encuentra en los términos "turismo" y "médico", dado que "turismo" implica ocio, diversión y actividades de vacaciones y "médico" alude a intervenciones, riesgo y dolor, favorece la urdimbre del tejido turístico, pues el turismo de salud, como concepto globalizador del turismo médico, se sustenta sobre el entrelazamiento de establecimientos, ofertas y servicios procedentes, en principio, de ámbitos no compartidos, reforzando de este modo el tejido turístico local y abriendo nuevos cauces de negocio.

Finalmente, al considerar su sentido motivacional, cabe preguntar acerca de la relación, en el turismo de salud, entre el comportamiento y la situación. Ambas regidas por propiedades de inmediatez y claridad. Es obvio, que el sentido motivacional se encuentra estrechamente vinculado a las motivaciones personales o escala de valores, y éstos, como 
es conocido, resultan variables o concordantes según el contexto cultural y social. Estas motivaciones, en realidad, se encuentran estrechamente vinculadas a los fundamentos a los cuales nos hemos venido refiriendo en este artículo. Pero no únicamente, pues también existen situaciones que actúan eficazmente a modo de soporte y sin las cuales no sería posible la implantación de una cierta actividad. Nos referimos a la gama de estructuras o agentes cuya actividad cabría considerar perteneciente a un estrato terciario, es decir: aeropuertos, vías de comunicación terrestre eficaces, servicios logísticos, infraestructura cultural y turística en general, comercio, centros de investigación y universidades, asociaciones, organismos y administración, así como espacios naturales idóneos, concretamente unas condiciones geográficas, en sentido amplio, saludables. Esta gama que hemos denominado de situación, si es percibida por los destinatarios con un carácter de inmediatez y claridad, pueden decantar la decisión personal a la hora de favorecer la satisfacción de las distintas motivaciones. En la provincia de Alicante es una realidad, consecuencia de la conjunción entre geografía física y acción antrópica, la existencia de recursos naturales óptimos y de un desarrollado tejido de estructuras y agentes sustentadores de la actividad turística que otorgan sentido y eficacia al turismo de salud.

\section{CONCLUSIONES}

La cuestión clave es concretar el sentido del concepto turismo de salud en la provincia de Alicante, y para dar respuesta a esta pregunta de investigación cabe exponer, a modo de conclusión, dos posibles perspectivas. La primera desvelará su estructuración desde las modalidades de turismo de salud, mientras que la segunda lo hará desde los fundamentos.

Respecto a las modalidades, en la provincia de Alicante el turismo médico está representado por siete hospitales y treinta y cinco clínicas, es decir cuarenta y dos centros en total. En el turismo termal / rehabilitación existen cinco clínicas de rehabilitación. En la modalidad de turismo medical wellness aparecen veintiún establecimientos y en turismo wellness un total de sesenta y ocho establecimientos. Estas cifras otorgan la predominancia a la modalidad wellness, pero también ponen al descubierto el elevado número de establecimientos de turismo médico. El turismo wellness y el médico son modalidades que se practican en los establecimientos que hemos considerado "puros", mientras que las modalidades de medical wellness y turismo termal / rehabilitación, resultan "mixtas". En Alicante existen veintiséis establecimientos de este tipo, pero su importancia no es menor, pues su actuación transversal fortalece el conjunto (véase el cuadro 1).

En cuanto a los fundamentos, si se aplica al turismo de salud, se percibe que, en la modalidad de turismo médico, el cuarenta y tres por ciento de los centros están especializados en fertilización humana asistida, su actividad por consiguiente deriva de un amparo legal específico, es decir, en terminología de Kaspar, del "sistema de orden superior político". El resto ofrecen otras especialidades médicas vinculadas al "sistema de orden superior sociocultural”, como la cirugía plástica/estética (véase el cuadro 2).

Por otra parte, considerando el número total de establecimientos, la modalidad wellness mantiene una acción dominante en la provincia y centra su atención en los servicios de "belleza", "medicina complementaria y alternativa" y "nutrición y dieta saludable"; a la par que medical wellness es mayoritario en "better aging", "saluto correctness", "desin- 
toxicación" y "new age" (véase el cuadro 4). Ahora bien, considerando cualitativamente estas dos modalidades, se observa una mayor coherencia y concentración en medical wellness, lo cual quiere decir que esta modalidad mantiene una mayor especialización sobre la gama de los fundamentos que la modalidad wellness (véase el cuadro 5).

No parece desacertado afirmar que el turismo de salud en la provincia de Alicante ha alcanzado un nivel de consolidación y desarrollo notable. El número de establecimientos en turismo médico y turismo wellness, conjuntamente con la cohesión que le proporciona la transversalidad y el número de establecimientos en la modalidad medical wellness así lo indican. Sin embargo, la atenta observación de lo anterior, también pone al descubierto la existencia de fundamentos con escaso o nulo crecimiento, por ejemplo: "saluto correctnes" y "new age", susceptibles de ser ofertados también desde la modalidad wellness. Asímismo, "nutrición y dieta saludable", aun siendo muy demandada, se encuentran relativamente poco implantada en la modalidad wellness (38\%), del mismo modo el fundamento "betteraging", escasamente atendido en wellness (18\%). Cabe recordar al respecto los índices de esperanza de vida alcanzados en la población europea en general y la alta recepción de esta población en la provincia de Alicante. Por último, es de destacar con respecto al fundamento "medicina complementaria y alternativa" (CAM), el desarrollo alcanzado por ésta en medical wellness (71\%), pero sobre todo llama la atención en esta modalidad la escasa implantación de ofertas basadas en medicina tradicional china u homeopática (véase el cuadro 5).

Finalmente, se sugiere de forma somera alguna medida que, se entiende, podría mejorar la posición competitiva del turismo de salud en Alicante. En primer lugar, y de modo genérico, parece ventajosa para los establecimientos la elaboración estratégica de una situación única de ventas (unique selling proposition), es decir, la identificación de una singularidad única de negocio capaz de proporcionar al establecimiento una identidad clara y distinta, por ejemplo: tipo de cliente objetivo, localización, o integridad de oferta, cualesquiera de ellas idóneas para aportar ventajas competitivas. Así como la ampliación de ofertas de actividades formativas en áreas de salud y bienestar, y no meramente ofrecer servicios en estas áreas. Del mismo modo sería conveniente la formación continua de empleados. Muy positiva resultaría asimismo la extensión del uso de los certificados de calidad en el mayor número posible de establecimientos (calidad turística de salud, wellness hotels, etc.).

Con respecto a las clínicas y hospitales, parece conveniente que éstos usen con mayor amplitud la oferta turística del destino, destacando el sentido de destino turístico y sus sinergias, e incluso que exploren más ampliamente las posibilidades de cooperación entre clínicas y hospitales de un lado, y establecimientos turísticos de otro. De igual modo, se trataría de ampliar los servicios médicos en los hoteles, así como los de medicina complementaria y alternativa.

Declaración responsable: La autora declara que no existe ningún conflicto de interés relacionado con la publicación de este artículo. 


\section{BIBLIOGRAFÍA}

ARDELL, D.(1977): High Level Wellness. Berkeley, Ten Speed Press.

ARDELL, D. (1986): High Level Wellness. $2^{\text {nd }}$ Edition, Berkeley, Ten Speed Press.

BERTALANFFY, L. (1967): Robots, Men and Minds. New York, George Braziller.

BERTALANFFY, L. (1968): General System Theory. New York, George Braziller.

BIEGER, T. (2006): Management von Destinationen. München,Oldenbourg.

BÜNTEN, Katrin (2011): Medizintourismus als touristische Positionierungsstratege der neuen EU-Beitrittsländer: Angebot und Nachfrage im Markt des Medizintourismus in Polen. Hamburg, Kovač.

BUNDESMINISTERIUM FÜR WIRTSCHAFT UND TECHNOLOGIE (BMWi)(2011): Innovativer Gesundheitstourismus in Deutschland, Leitfaden. Berlin, BMWi.

CARRERA, P.M. y BRIDGES, J.F.P. (2006): «Globalization and Healthcare: Understanding Health and Medical Tourism», Expert Review of Pharmacoeconomics and Outcomes Research, vol. 6 (4), pp. 447-454.

COHEN, E. (2008): «Medical Tourism in Thailand», en Cohen, E. (Ed.) Explorations in Thai Tourism. West Yorkshire, Emerald.

CONNELL, J. (2006): «Medical tourism: Sea, sun, sand and ... surgery», Tourism Management, vol. 27, pp. 1.093-1.100.

CONNELL, J. (2008): «Tummy Truck and the Taj Mahal? Medical Tourism and the Globalization of Health Care», en Woodside A.G. y Martin, D. (Eds.) Tourism Management. Oxfordshire, Cabi, pp. 232-244.

CONNELL, J. (2011): Medical Tourism. Oxford shire, Cabi.

CONNELL, J. (2013): «Contemporary Medical Tourism: Conceptualisation, Culture and Comodification», Tourism Management, vol. 34, pp. 1-13.

CUERVO, R.S. (1967): El Turismo como Medio de Comunicación Humana. México, D.F., Departamento de Turismo del Gobierno de México.

DEUTSCHER WELLNESS VERBAND (DWI) (2019): Medical Wellness: Lebenstil-Medizin. Disponible en https://www.wellnessverband.de.

DUNN, H. L. (1959): «High-level Wellness for man and society», American Journal of Public Health, vol. 49 (6), pp. 786-792.

DUNN, H. L. (1961): High Level Wellness. Arlington, VA., Beatty Press.

EGGERTSON, L. (2006): «Wait-list weary Canadians seek treatment abroad», Canadian Medical Association Journal, vol. 174 (9), p. 1.247.

EHRBECK, T., GUEVARA, C. y MANGO, P. (2008): «Mapping the Market for Medical Travel», McKinseyQuartely, May.

ERFURT-COOPER, P. (2014): «Wellness tourism: a perspective from Japan», en Voigt, C., y Pforr, C., (Eds.) Wellness Tourism: a destination perspective. London, New York, Routledge, pp. 235-254.

ERFURT-COOPER, P. y COOPER, M. (2009): Health and Wellness Tourism. Spas and Hot Springs. Bristol, Channel View Publications.

EUROPÄISCHES WELLNESS INSTITUT (EWI) (2019): Letter of Intent. Disponible en https://www.wellnesshotels-resorts.de/de/medical-wellness-letter-of-intent. 
GETZ, D. (1986): «Models in tourism planning: towards integration of theory and practice», Tourism Management, vol. 7 (1), pp. 21-32.

GOODRICH, J. y GOODRICH, G. (1987): «Health-care tourism-an exploratory Study», Tourism Management, vol. 8 (3), pp. 217-222.

GROß, M. (2017): Gesundheitstourismus. Stuttgart, UTB.

HALL, C. M. (2011): «Health and Medical tourism: a kill or cure for global public health», Tourism Review, vol. 66 (1-2).

HAUG, C.V. (1991): Gesundheitsbildung im Wandel. Bad Heilbrunn, Universität Augsburg.

HEELAS, P. (1996): The New Age Movement: The celebration of the self and the sacralization of modernity. Oxford, Blackwell.

ILLING, K. (2000): Patientenimport und Gesundheitstourismus. Internationales Marketing für Kliniken, Kurorte und Gesundheitsregionen. Berlin, TDC.

ILLING, K. (2002): Medical Wellness und Selbstzahler. Zur Erschließung neuer Märkte für Rehabilitations- und Kurkliniken und Sanatorien. Berlin, TDC.

ILLING, K. (2004): «Medical Wellness in Hotels und Kliniken - Erfolgsvoraussetzung für Selbstzahlermedizin», Spektrum Freizeit, vol. 2, pp. 13-36.

ILLING, K. (2009): Gesundheitstourismus und Spa-Management. München, Oldenbourg.

KAGELMANN, J. y KIEFL, W. (2016): Gesundheitsreisen, Gesundheitstourismus; Grundlagen und Lexikon.München, Profil Verlag.

KASPAR, C. y FEHRLIN, P. (1984): Marketingkonzeption für Heilbäderkurorte. Bern, Haupt.

KASPAR, C. (1978): Die Anwendung der Systemtheorie zur Lösung methodischer Probleme der Fremdenverkehrswissenschaft und-wirtschaft. Festschrift Prof. Bernecker. Wien, Manz.

KASPAR, C. (1995): «Zielsetzung der Arbeitstagung, en Institut für Tourismus und Verkehrswirtschaft», en Gesundheitstourismus 2000: Perspektiven und Angebotsgestaltung, Hochschule St. Gallen, pp. 5-6.

KASPAR, C. (1996a): Die Tourismuslehre im Grundriss. Bern, Haupt.

KASPAR, C. (1996b): «Gesundheitstourismus im Trend», Jahrbuch der Schweizer Tourismuswirtschaft,1995/96.

KRCZAL, E. (2011): «Qualitätsstandards für Medical Wellness», en Krczal, A.,Krczal, E.,Weiermair, K. (Eds.) Kundenorientierung und hohe Standards. Berlin, Schmidt Verlag.

KRIPPENDORF, J. (1984): Die Ferienmenschen. Für ein neues Verständnis von Freizeit und Reisen. Zürich und Schwäbisch Hall, Orell Füssli.

LANZ-KAUFMANN, E. (1999): Wellness-Tourismus in der Schweiz-Qualitätsanforderungen an die Hotellerie. Universität Bern.

LANZ-KAUFMANN, E. (2002): Wellness: Tourismus. Universität Bern.

LEIPER, N. (1990): Tourism Systems: An Interdisciplinary Perspective. Palmerston North, Massey University.

LOHMANN, G. y PANOSSO, A. (2017):Tourism Theory. Concepts, Models and Systems. Oxfordshire, Cabi.

LUNT, N. y CARRERA, P., (2010): «Medical tourism: Assessing the evidence on treatment abroad», Maturitas, vol. 66 (1), pp. 27-32. 
LUNT, N. y CARRERA, P., (2011): «Systematic review of web sites for prospective medical tourists», Tourism Review, vol. 66 (1-2), pp. 57-67.

MACREADY, N. (2007): «Developing countries court medical tourists», Lancet, vol. 369 (9.576), pp. 1.849-1.850.

MEDICAL WELLNESS ASSOCIATION (MWA): «Defining Medical Wellness. Definitions of Terms, Dimensions of Medical Wellness». Disponible en https://www. medicalwellnessassociation.com/wp-content/uploads/2017/08/Defining-Medical-Wellness-Definition-of-Terms-Breuleux-C.-2017-1.pdf.

MILL, R.C. y MORRISON, A. (1987): The tourism system: An introductory text. New Jersey, Prentice-Hall.

MILSTEIN, A. y SMITH, M. (2006): «America's new refugees - seeking affordable surgery offshore», New England Journal of Medicine, 355, pp. 1637-1640.

MÜLLER, H. (1997): Freizeit und Tourismus. Eine Einführung in Theorie und Politik. Universität Bern.

MÜLLER, H. y LANZ-KAUFMANN, E. (2000): «Eine Analyse des Schweizer Marktes und Konsequenzen für die Hotellerie», Tourism Review, vol. 55 (2), pp. 26-38.

MÜLLER, H. y LANZ-KAUFMANN, E. (2001): «Wellness tourism. Market analysis of a special health tourism segment and implications for the hotel industry», Journal of Vacation Marketing, vol. 7 (1), pp. 5-17.

NAHRSTEDT, W. (1996): «Kurtourismus: Innovation oder Kapitulation? Der schwierige Weg der Heilbäder zu 'postmodernen' Gesundheitszentren», Heilbad und Kurort, vol. 48 (1946), 10, pp. 264-266.

OLCINA, J. y MIRÓ J. J. (2016): «El clima, recurso básico del turismo alicantino. De la valoración del clima invernal al aprovechamiento intensivo del clima estival», Canelobre, $\mathrm{n}^{\circ} 66, \mathrm{pp} .18-37$.

OPASCHOWSKI, H. (1987): Pädagogik und Didaktik der Freizeit. Opladen, Leske und Budrich.

REISMANN, D. (2010): Health Tourism. Social Welfare through International Trade. Cheltenham, Edward Elgar.

ROSOWSKI, K. (2008): Zukunktsmarkt Pflegehotel. Eine Marktanalyse. München, Grin. RULLE, M. (2008): Gesundheitstourismus in Europa. Entwicklungstendenzen und Diversifikationsstrategien. München, Profil.

RULLE, M., HOFFMANN, W. y KRAFT, K.(2010): Erfolgsstrategien im Gesundheitstourismus: Analyse zur Erwartung und Zufriedenheit von Gästen. Berlin, Schmidt.

SCHOBERSBERGER, W. et al. (2006): «Kundennutzenstiftung durch Kooperation von Medizin und Tourismuswirtschaft», en Krczal, E., Krczal, A. y Weiermair, K. (Eds.) Wellness und Produktentwicklung. Berlin, Schmidt.

SMITH, M. y KELLY, C. (2006): «Holitisc Tourism: Journey of the Self?», Journal of Tourism Recreation Research, vol. 31 (1), pp. 15-24.

SMITH, M. y PUCZKÓ, L. (2013): Health and Wellness Tourism. London, New York, Routledge, primera ed. 2009.

SMITH, M. y PUCZKÓ, L. (2014): Health, Tourism and Hospitality: Spas, Wellness and Medical Travel. London, New York, Routledge. 
POLLOCK, A. y WILLIAMS, P. (2000): «Health tourism trends: closing the gap between health care and tourism», en Lime, D. y Gartner W. (Eds.) Trends in Outdoor Recreation, Leisure and Tourism, New York, Cabi, pp. 165-174.

SOBO, E. (2009): «Medical travel: what it means, why it matters», Medical Anthropology, vol. 28, pp. 326-335.

ULRICH, H. (1968): Die Unternehmung als produktives soziales System. Bern, Haupt.

VV.AA. (2016): «El turismo en Alicante y la Costa Blanca», Canelobre, $\mathrm{n}^{\circ}$ 66. Diputación de Alicante.

VERA, J.F. (1987): Turismo y urbanización en el litoral alicantino. Alicante, Instituto Alicantino de Cultura Juan Gil-Albert.

VOIGT, C. (2014): “Towards a conceptualization of wellness tourism”, en Voigt, C. y Pforr, C. (Eds.) Wellness Tourism, A destination Perspective. London, New York, Routledge, pp. 19-44.

VOIGT, C. y LAING, J. (2013): «A Way Through the Maze: Exploring Differences and Overlaps Between Wellness and Medical Tourism Providers», en Botterill, D., Pennings, G., Mainil, T. (Eds.) Medical Tourism and Transnational Health Care. London, New York, Palgrave Macmillan, pp. 30-47.

VOIGT, C. y PFORR, C. (2014): Wellness Tourism. A destination Perspective. London, New York, Routledge.

WEIERMAIR, K. y STEINHAUSER, C. (2003): «New tourism clusters in the field of sports and health: the case of Alpine Wellness». 12 Simposio Internacional de Turismo y Ocio. Barcelona.

WOODMAN, J. (2008): Patients Beyond Borders. Chapel Hill, Healthy Travel Media.

WORD TOURISM ORGANISATION AND EUROPEAN TRAVEL COMMISSION (UNWTO) (2018): Exploring Health Tourism. Executive Summary. Madridy Bruxelles, World Tourism Organisation, European Travel Commission. 